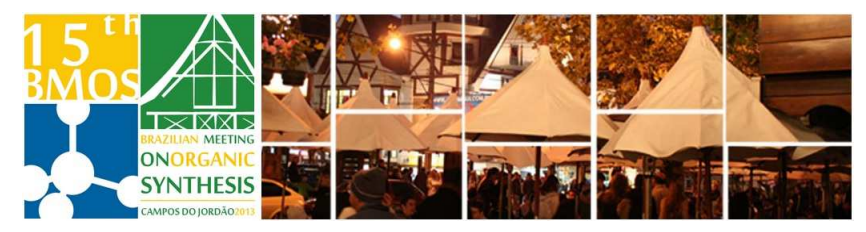

\title{
A high enantioselective Proline-based helical polymer catalyst for aldol type reaction
}

\author{
George H. Sakae, Leandro M. Takata, Antonio S. Paulino, Reinaldo C. Bazito, \\ Rafael F. Cassaro, Cleverson Princival and Alcindo A. Dos Santos* \\ University of São Paulo, Institute of Chemistry, Av. Prof. Lineu Prestes, 748, São Paulo, SP, Brazil. \\ *alcindo@iq.usp.br:
}

Keywords: helical polymers, stereoselectivity, proline catalysis

\section{INTRODUCTION}

The induction of chirality still a very intricate and exciting research area being the organocatalysis one of the most recent focus of investigation. Helical chirality is present on nature. Inspired on this asymmetric concept, some synthetic helical compounds, especially polymers have ben applied for asymmetric synthesis ${ }^{1}$, enantiomeric separations ${ }^{2}$ and studies related to the properties of liquid crystalline compounds ${ }^{3}$. The preferential helicity of a polymer can be induced by the nature of the pendant molecular residue. Many applications have ben found for this kind of molecules.

Recently we have proposed the synthesis of helical polymers for catalytic application since the recovery of a polymer from the reaction media can be easier then a smaller parent compound. In addition, we wonder if the helicity could play some role on the chirality induction. In this way, we designed and synthesized a proline-based helical polymer and subjected it to aldol reaction.

\section{RESULTS AND DISCUSSION}

In figure 1 is presented a proline-based polymercatalyzed (Poly-1) aldol reaction model between cyclohexanone and $p$-nitrobenzaldehyde.
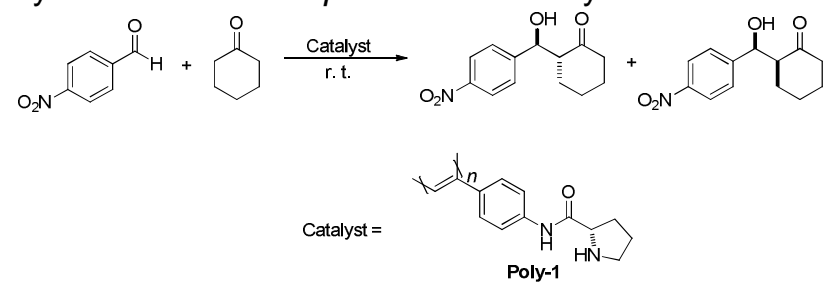

Figure 1. helycal polymer catalyzed aldol reaction

In $2011 \mathrm{Fu}$ reported ${ }^{4}$ a proline catalyzed aldol reaction using the same starting materials under similar reaction condition and the achieving Using similar reaction condition giving the product in $72 \%$ isolated yield and 68\%(58\%) anti(syn) enantiomeric excess respectivelly. The Poly-1 catalyst allows the isolation of the same product in $78 \%$ yield and an enantiomeric excess of 91(53) anti(syn) respectively.
In order to optimize the reaction conditions we carried out other experiments and the results are presented in Table 1. As can be seen, best results were achieved by using $20 \mathrm{~mol} \%$ of both, the catalyst and $\mathrm{AcOH}$ as additive. Similar good yields and e.e. were also achieved by using higher amount of the catalyst without additive.

Table 1 - Reaction condition optimization

\begin{tabular}{ccccccc}
\hline entry & $\begin{array}{c}\text { Cat. } \\
(\mathbf{m o l} \%)\end{array}$ & Addit. $^{{ }^{2}}$ & $\mathbf{t}(\mathbf{h})$ & $\boldsymbol{\eta}_{(\%)}$ & anti:syn $^{2}$ & e.e. anti (syn) \\
\hline 1 & 10 & - & 72 & 81 & $75: 25$ & $60(50)$ \\
2 & 5 & - & 72 & 60 & $80: 20$ & $53(40)$ \\
3 & 10 & - & 72 & 78 & $85: 15$ & $69(50)$ \\
4 & 10 & AcOH & 48 & 85 & $80: 20$ & $73(60)$ \\
5 & 20 & - & 48 & 77 & $88: 12$ & $78(50)$ \\
6 & 20 & AcOH & 24 & 78 & $75: 25$ & $91(53)$ \\
7 & 30 & - & 24 & 75 & $86: 14$ & $92(43)$ \\
\hline
\end{tabular}

\section{CONCLUSION}

$C D$ analysis of the polymer confirms the presence of a preferential helical orientation. If the enantiomeric excess were a result resultant only from the proline sterocenter on the transition state, no significant improvement of the e.e. would be observed. Albeit not yet elucidate the role of the helicicity on the observed e.e., the results corroborate such proposition. The recovery of the catalyst for reuse is possible and other substrates are under investigation for the same transformation.

\section{ACKNOWLEDGEMENTS}

The authors are grateful for the financial and structural support offered by the University of São Paulo through the NAP-CatSinQ (Research Core in Catalysis and Chemical Synthesis), FAPESP, CAPES and CNPq for financial support.

\section{REFERENCES}

${ }_{1}^{1}$ Yashima, E. J. Polym. Sci. Pol. Chem.2011, 49, 5192-5198.

${ }^{2}$ Tamura, K.; Miyabe, T.; Iida, H.; Yashima, E. Polym. Chem. 2011, 2, 91-98.

${ }^{3}$ Suda, K.; Akagi, K. Macromolecules 2011, 44, 9473-9488.

${ }^{4} \mathrm{Fu}, \mathrm{X}$. et al., Tetrahedron, 22, 840-850, 2011 